American Journal of Applied Sciences 4 (3): 128-132, 2007

ISSN 1546-9239

(C) 2007 Science Publications

\title{
Preparation and Properties of Copolyanhydrides Based on 2-Hexadecylsuccinic Acid and Sebacic Acid
}

\author{
Yousef Hamdan, Xiangmei Jiang, Kaixun Huang and Kaichao Yu \\ Department of Chemistry, Huazhong University of Science and Technology, Wuhan, 430074
}

\begin{abstract}
Poly(2-hexadecylsuccinic acid-sebacic acid) (P(HSA-SA)) copolymers have been prepared by melt polycondensation. The copolymers were characterized by FT-IR, ${ }^{1} \mathrm{HNMR}$, gel permeation chromatography (GPC), differential scanning calorimetry (DSC) and thermal gravimetric analysis (TGA). In vitro studies showed that all our prepared copolymers are degradable in phosphate buffer at $37{ }^{\circ} \mathrm{C}$. The release profiles of hydrophilic model drug, ciprofloxcin hydrochloride, from the copolymers, follow first order release kinetics. All the preliminary results suggested that the copolymer might be potentially used as drug delivery devices.
\end{abstract}

Key words: Polyanhydrides, melt polycondensation, in vitro degradation, drug released

\section{INTRODUCTION}

Polyanhydrides have been considered to be useful biomaterials as carriers of drugs to various organs of the human body such as brain, bone, blood vessels and eyes. They can be prepared easily from available, low cost resources. They have hydrophobic backbone with hydrolytically labile anhydride linkages and can be controlled by manipulation of the polymer composition. Polyanhydrides are biocompatible and degrade in vivo into nontoxic dicarboxylic acids in predictable rates and patterns counterparts that are eliminated from the body as metabolites. Recent studies on polyanhydrides as drug carriers show that the anhydrides degrade in a controlled fashion and are biocompatible with the human body tissues including the brain ${ }^{[1,2]}$.

Fatty acids are suitable candidates for the preparation of biodegradable polymers as they are biocompatible, hydrophobic and can be manipulated to meet desirable characteristics.

The incorporation of fatty acids in the polyanhydride backbone tends to retain the encapsulated drug for longer time periods and therefore, could be useful for controlled drug-release. Polyanhydrides have been synthesized from dimer and trimer unsaturated fatty acids ${ }^{[3-5]}$ and other fatty acids ${ }^{[6-}$ ${ }^{8]}$. The dimers of oleic acid and erucic acid are liquid oils containing two carboxylic acids available for anhydride polymerization. The homopolymers are viscous liquids and copolymerization with increasing amounts of sebacic acid forms solid polymers having increasing melting points as a function of SA content.
In surface erosion, water can not penetrate into the bulk of the matrix due to the hydrophobicity of the polymer and hence only the labile bonds on the surface are hydrolyzed leading to surface erosion. Therefore, to maximize control over the release process, it is desirable to have a polymeric system which degrades only from the surface. Achieving such a heterogeneous degradation requires the rate of hydrolytic degradation on the surface to be much faster than the rate of water penetration into the bulk. The ideal polymer would have a hydrophobic backbone, but with a water labile linkage. Copolyanhydrides of 2-hexadecylsuccinic acid and sebacic acid are expected to undergo pure surface erosion due to the high lability of the anhydride bonds on the surface and the hydrophobicity of hexadecyl substituent, which prevents water penetration in to the bulk.

In this study, we synthesized a novel copolyanhydrides derived from 2-hexadecylsuccinic acid (HSA) and sebacic acid. Preparation, characterization, in vitro biodegradation and release profiles of hydrophilic ciprofloxcin hydrochloride are reported in this work.

\section{MATERIALS AND METHODS}

Ciprofloxcin hydrochloride was purchased from Tianjing Central Pharmaceutical Corp., Ltd (Tianjing, China).

Stearic acid (mp 69 70 ${ }^{\circ} \mathrm{C}$ ), analytically pure reagents of bromine, diethyl malonate, sodium and red phosphorus, were purchased from Shnghai Chemical Reagents Factory (Shnghai, China).

Corresponding Author: Kaichao Yu, Department of Chemistry, Huazhong University of Science and Technology, Wuhan, 430074, Tel: 0-86-27-62876833 
Analytically pure sebacic acid was also purchased from Shnghai Chemical Reagents Factory (Shnghai, China) and recrystallized twice from ethanol. Acetic anhydride was refluxed over magnesium strips and distilled, bp 139 142 ${ }^{\circ} \mathrm{C}$ before use. All the solvents were dried over $4 \mathrm{~A}$ molecular sieve and distilled before use.

Instruments: IR spectra were obtained with a burker EQUINOX55 FT-IR spectrometer. Ethyl 2Bromooctadecanoate and Polymer samples were prepared in dichloromethane and cast onto $\mathrm{NaCl}$ plates for recording IR spectra. 2-hexadecylsuccinic acid was pressed into $\mathrm{KBr}$ pellet directly.

${ }^{1}$ HNMR spectra were obtained on a Bruker AV400 (DQX400) NMR spectrometer, with $\mathrm{d} 6-\mathrm{CD}_{3} \mathrm{Cl}$ as solvent and tetramethylsilane (TMS) as internal standard.

Thermal analyses were performed on a Perkin Emer system consisting of DSC 7 and TGA 7 analyzer with TAC7/DX instrument controller. Data were processed using UNIX thermal analysis system software on a DEC computer station. For DSC, an average sample weight of $5 \sim 10 \mathrm{mg}$ was heated at $10^{\circ} \mathrm{C}$ $\min ^{-1}$ under argon atmosphere. DSC measured the melting point and the heat of fusion. For TGA, an average sample weight of $10 \mathrm{mg}$ was heated at $10^{\circ} \mathrm{C}$ $\mathrm{min}^{-1}$ under a flow of argon. The decomposition temperature was detected by TGA.

The molecular weights of the polymers were determined on a Waters GPC system consisting of a water 600 pump, Water 410 Differential Refractive Index detector. Samples were eluted in dichloromethane through a Vaian MicroPak G4000 and G3000 column installed in series at a flow rate of $1.0 \mathrm{~mL} \mathrm{~min}^{-1}$. molecular weight were determined relative to narrow dipresed polystyrene standards with a molecular weight range from 1000 to 200,000 .

Synthesis of ethyl 2-bromooctadecanoate: Stearic acid (46 g, $0.1618 \mathrm{~mol})$ was heated with $13 \mathrm{~mL},(0.179$ mol) of thionyl chloride for $90 \mathrm{~min}$. the produced octadecanoyl chloride was allowed to cool and $0.05 \mathrm{~g}$ of red phosphorus was added. The mixture was gently refluxed and $10 \mathrm{~mL}(0.193 \mathrm{~mol}$.) of dry bromine was introduced during $6 \mathrm{hrs}$. Reflux was continued until the evolution of hydrogen bromide was ceased (12 hrs). The produced 2-Bromooctadecanoyl chloride was allowed to cool and $50 \mathrm{~mL}$ of absolute ethanol was added during $2 \mathrm{hrs}$. The reaction was completed by heating on water bath for $4 \mathrm{hrs}$. Low boiling point fractions and excess ethanol were removed by distillation at normal pressure. The crude Ethyl 2Bromooctadecanoate was dissolved in Tetrachlorocarbon and washed with water, sodium hydrogen carbonate solution and water. The solution was dried over calcium sulphate and distilled at normal pressure to remove Tetrachlorocarbon and then under vacuum $(1.6 \mathrm{mmHg})$ at $174-177^{\circ} \mathrm{C}$., $45 \mathrm{~g}$ of Ethyl 2Bromooctadecanoate was obtained.

Synthesis of 2-hexadecylsuccinic acids: To a solution of $2.62 \mathrm{~g}(0.114 \mathrm{~mol})$ of sodium in $75 \mathrm{~mL}$ of absolute ethanol, $18.3 \mathrm{~g}(0.1143 \mathrm{~mol})$ of diethyl malonate was added dropwise at $70^{\circ} \mathrm{C}$. After stirring for 30 minutes at $70^{\circ} \mathrm{C}, \quad 44.5 \quad \mathrm{~g} \quad(0.1136 \mathrm{~mol})$ of Ethyl 2Bromooctadecanoate was added over a period of 10 min. The reaction mixture was then refluxed for $18 \mathrm{~h}$. The excess base was neutralized with acetic acid and ethanol was evaporated under reduced pressure, water was added to dissolve the inorganic salts and the layers separated. Aqueous layer was extracted with $100 \mathrm{~mL}$ of diethyl ether and combined with the above crude ester. The solution was dried with $\mathrm{Na}_{2} \mathrm{SO}_{4}$, filtered and the solvent was removed under reduced pressure. The viscous oil $(53.82 \mathrm{~g})$ was purified by column chromatography on silica gel, using hexane/ $\mathrm{CH} 2 \mathrm{Cl} 2$ (1:1). $27 \mathrm{~g}$ was obtained. The produced ester was hydrolyzed by heating under reflux with $43.3 \mathrm{~g} \mathrm{KOH}$ dissolved in $50 \mathrm{~mL}$ water and $150 \mathrm{~mL}$ ethanol. After distillation of ethanol and acidification with $6 \mathrm{~N}$ sulfuric acid, the acidic solution was extracted with diethyl ether. The solvent removed by distillation to afford crude tricarboxylic acid which was decarboxylated by Heating at $135 \sim 140{ }^{\circ} \mathrm{C}$. The crude 2hexadecylsuccinic acid was dissolved in diethyl ether and treated with decolorizing charcoal. After evaporation of the solvent the product was recrystallized from acetic acid, $17.5 \mathrm{~g}$ of 2hexadecylsuccinic acid was obtained, $\mathrm{mp} 89-90{ }^{\circ} \mathrm{C}$.

Preparation of polymers: Copolyanhydrides were prepared from the reaction of acids mixture (sebacic acid and 2-hexadecylsuccinic acid) with excess of acetic anhydride under reflux for $30 \mathrm{~min}$ in a flask with side arm equipped with a capillary nitrogen inlet. The solution was allowed to cool to room temperature and excess solvent was removed at $70{ }^{\circ} \mathrm{C}$ under reduce pressure. Potassium acetate 1 molar percent was added then prepolymer underwent melt-polycondensation directly for $90 \mathrm{~min}$ at $180{ }^{\circ} \mathrm{C}$, high vacuum $(1 \mathrm{~mm} \mathrm{Hg})$ was applied. During the polymerization a strong nitrogen sweep with vigorous agitation of the melt was performed for $30 \mathrm{~s}$ every $15 \mathrm{~min}$. The crude polymer was 
dissolved in dichloromethane and the catalyst was removed from the polymer solution by filtration. Polymer was precipitated in dry petroleum ether from a dichloromethane solution two times. The polymer was dried under vacuum at room temperature over $\mathrm{P}_{2} \mathrm{O}_{5}$.

In vitro degradation and drug release: Samples of polymer in a rod shape $(5 \mathrm{~mm}$ diameter, $10 \mathrm{~mm}$ long, about $125 \mathrm{mg}$ ) were prepared by melting at $80{ }^{\circ} \mathrm{C}$ in Teflon mold. The drug-loading device $(20 \%$ ciprofloxcin) was prepared by sieving polymer and drug to $100 \sim 150 \mu \mathrm{m}$ and melted in the same Teflon mold used to prepare polymer samples for degradation. All polymer samples and devices of fixed dimensions were submitted to degradation in $25 \mathrm{~mL}$ of $0.1 \mathrm{M}$ phosphate buffer at $\mathrm{PH} 7.4$ and $37{ }^{\circ} \mathrm{C}$ under gentle shaking. The solution was replaced daily with fresh buffer. At each time point, the polymer was freezedried and the hydrolysis of the polymer was monitored by weight loss of polymer. Drug released was analyzed by measuring the absorbance of the release medium at $277 \mathrm{~nm}$ and on a UV/VIS spectrophotometer, Lambada Bio 40.

During the hydrolysis study, the surface and the core of the devices were monitored for the changes in their linkages by IR.

\section{RESULTS AND DISCUSSION}

Synthesis of monomer: 2-bromooctadecanoyl chloride was prepared by Hell-Volhard-Zelinsky reaction from stearic acid then it was esterificated directly. Infra red spectrum of Ethyl 2-bromooctadecanoate shows carbonyl absorption band $\mathrm{C}=\mathrm{O} 1742.7 \mathrm{~cm}-1$, stretching vibration band $\mathrm{O}=\mathrm{C}-\mathrm{O} 1263.83 \mathrm{~cm}-1$, band of ester (alcohol C-O stretch ) $1151.55 \mathrm{~cm}-1$ and $\mathrm{C}-\mathrm{Br}$ absorption band 721.82 .

2-hexadecylsuccinic acid was prepared by the condensation reaction of ethyl 2-bromooctadecanoate with diethyl malonate in the presence of Sodium ethoxide to give tricarboxylic esters followed by hydrolysis with alkali and decarboxylation by heating.

Infra red spectrum of 2-hexadecylsuccinic acid shows carbonyl absorption band $(\mathrm{C}=\mathrm{O}) 1700 \mathrm{~cm}-1$, broad O-H stretching band 2500-3300 cm-1, C-O-H inplane band $1415.14 \mathrm{~cm}-1, \mathrm{C}-\mathrm{O}$ stretching band 1285.59 and $\mathrm{O}-\mathrm{H}$ out of plane band 949.38 .

2-hexadecylsuccinic acid: ${ }^{1} \mathrm{HNMR}$ spectrum (400.132471 MHZ, CDCl3) shows the following chemical shift: ppm $0.9(\mathrm{t}, 3 \mathrm{H}), 1.26-1.38(\mathrm{~m}, 26 \mathrm{H})$, 1.5-1.6 (m, 4H), $2.56(\mathrm{~d}, 2 \mathrm{H}), 2.68-2.74(\mathrm{~m}, 1 \mathrm{H})$ (Fig. 1).

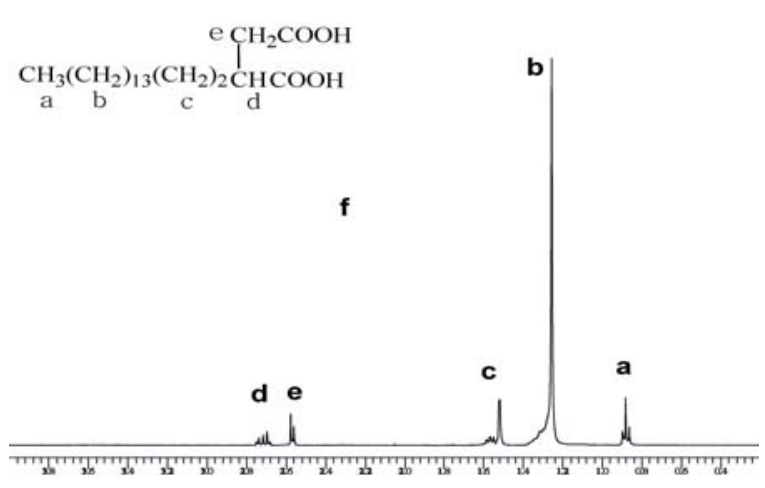

Fig. 1: $\quad{ }^{1}$ HNMR spectrum of 2-hexadecylsuccinic acid

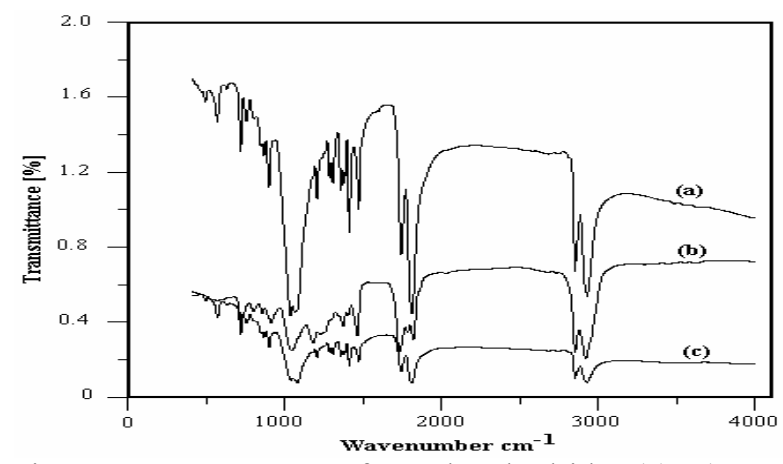

Fig. 2: $\quad$ FT-IR spectra of copolyanhydrides (a) P(HSASA) 10:90; (b) P(HSA-SA) 20:80; (c) P(HSASA) 50:50

Preparation of polymers: To reduce the probability of forming cyclic 2-hexadecylsuccinic anhydride a mixed prepolymer was prepared by refluxing acetic acid anhydride with mixture of 2-hexadecylsuccinic acid and sebacic acid followed by distillation until dryness. The mixed prepolymer then underwent meltpolycondensation at $180{ }^{\circ} \mathrm{C}$ under high vacuum $(1 \mathrm{~mm}$ $\mathrm{Hg}$ ). We have found adding potassium acetate increases the yield due to the rig opining reaction of unreacted cyclic-anhydride.

Copolyanhydride characterization: All polymers prepared were characterized by FT-IR. The IR spectra of HSA-SA copolyanhydrides show two stretching bands in the carbonyl region $\sim 1812$ and $1741-1743 \mathrm{~cm}-$ 1 and stretching band of C-CO-O-CO-C at 1041-1043 $\mathrm{cm}-1$ (Fig. 2). The IR spectra of HSA-SA copolyanhydrides does not show any bands over 3000 $\mathrm{cm}-1$, thus there are no $-\mathrm{COOH}$ groups existed in the copolymers. ${ }^{1} \mathrm{HNMR}$ spectrum (400.132471 MHZ, $\left.\mathrm{CDCl}_{3}\right)$ of copolyanhydride [P(HSA-SA)(HSA:SA 40:50)] shows the following chemical shift: ppm 0.899 $(\mathrm{t}, 3 \mathrm{H}), 1.20-1.41(\mathrm{~m}, 34 \mathrm{H}), 1.43-1.64(\mathrm{~m}, 8 \mathrm{H}), 2.55(\mathrm{~d}$, $2 \mathrm{H}), 3.04-3.11(\mathrm{~m}, 1 \mathrm{H}), 2.3$ (t,2H) (Fig. 3). 
Am. J. Applied Sci., 4 (3): 128-132, 2007

Table 1: Physical properties of poly( 2-hexadecylsuccinic acid-sebacic acid) copolymer [P(HSA-SA)]

\begin{tabular}{|c|c|c|c|c|c|c|c|}
\hline \multirow{2}{*}{$\begin{array}{l}\text { Theoretical } \\
\text { HSA ratio in } \\
\text { polymer } \mathrm{g} \%\end{array}$} & \multirow{2}{*}{$\begin{array}{l}\text { Gravimetrical } \\
\text { HSA ratio in polymer } \\
\mathrm{g} \%\end{array}$} & \multirow{2}{*}{$\begin{array}{l}\text { Yields } \\
(\%)\end{array}$} & \multirow{2}{*}{$\begin{array}{l}{ }^{\mathrm{a}} \mathrm{T}_{\mathrm{d}} \\
\left({ }^{\circ} \mathrm{C}\right)\end{array}$} & \multirow[b]{2}{*}{${ }^{\mathrm{b}} \mathrm{T}_{\mathrm{m}}\left({ }^{\circ} \mathrm{C}\right)$} & \multicolumn{2}{|c|}{${ }^{\mathrm{c}}$ Molecular weightc } & \multirow[b]{2}{*}{$\Delta \mathrm{H}^{\circ}(\mathrm{k} / \mathrm{J})$} \\
\hline & & & & & $\mathrm{Mw}$ & $\mathrm{Mn}$ & \\
\hline 10 & 9.42 & 89 & 239.949 & 76.76 & 39700 & 38110 & 138.685 \\
\hline 20 & 18.78 & 85 & 256.895 & 71.83 & 30940 & 30240 & 114.359 \\
\hline 30 & 28.08 & 82 & 248.332 & 66.61 & 30915 & 30110 & 62.641 \\
\hline 40 & 37.26 & 78 & 260.544 & 59.97 & 23900 & 22335 & 51.621 \\
\hline 50 & 46.45 & 75 & 247.555 & 55.01 & 15340 & 6180 & 13.906 \\
\hline
\end{tabular}

${ }^{a}$ Determined by TGA $;{ }^{b}$ Determined by DSC; ${ }^{\mathrm{c}}$ Determined by GPC using polystyrene as standard

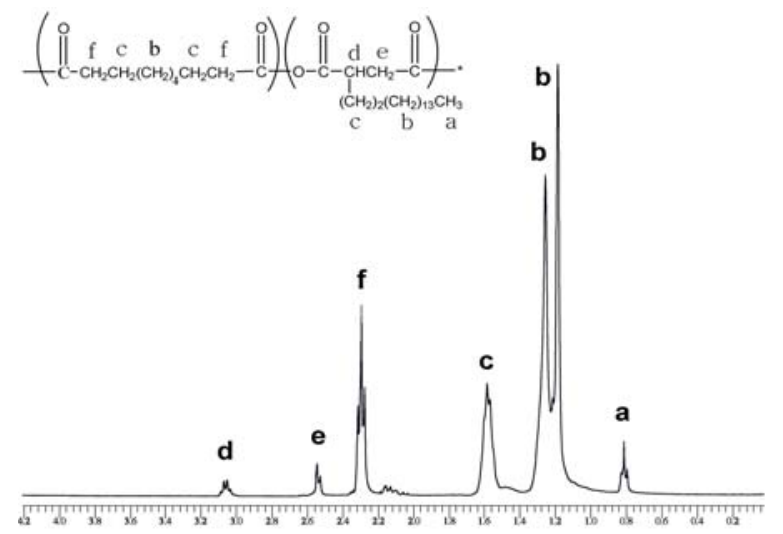

Fig. 3: ${ }^{1}$ HNMR spectrum of copolyanhydrides P(HSA-SA) 40:60

The polymer composition was determined quantitatively by hydrolyzing the polymer in a $1 \mathrm{~N}$ $\mathrm{NaOH}$ solution at $80^{\circ} \mathrm{C}$ for $24 \mathrm{~h}$ and the generated 2hexadecylsuccinic acid was separated by extraction with dichloromethane.

As shown in Table 1 the weight-average molecular weights of copolyanhydrides prepared in our work range from 15340 to over 39000 . As the sebacic acid content in copolyanhydride increase, the average molecular weight increases. Melting points Tm of all polymers are lower than $80{ }^{\circ} \mathrm{C}$ and their decomposition points $\mathrm{Td}$ are over $200^{\circ} \mathrm{C}$.

In vitro degradation: The degradation of polymers was performed by weight loss device and monitoring the disappearance of the anhydride linkages and formation of carboxylic acid by IR spectroscopy.

At any stage of the study the device remained intact. However, as a function of time, pores were observed in the surface of the device. As shown in Fig. 4 , the hydrolysis rate of the matrices decrease with the hydrophobic component (HSA) content in the polymer increases.

After 9 days degradation, the remnant solid porous was analyzed by IR for its anhydride content. Based on the IR results, the remnant solid is composed of the

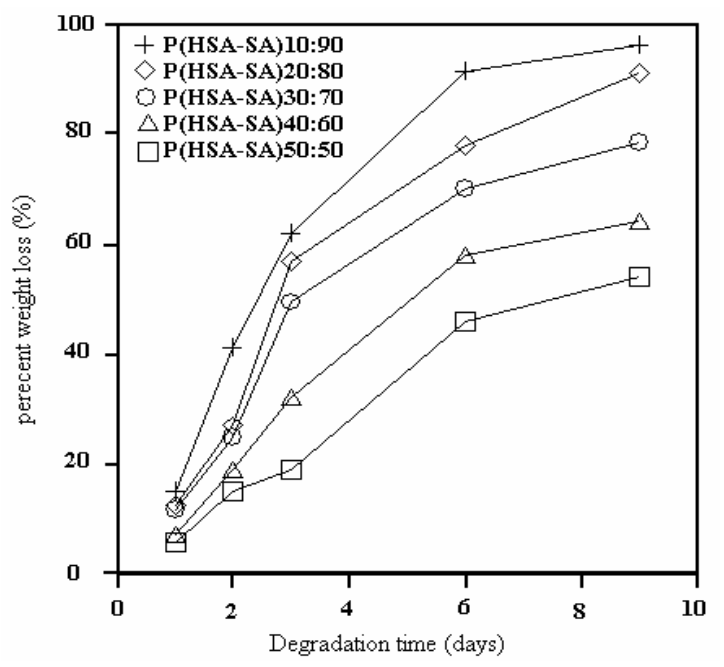

Fig. 4: Degradation profile of $\mathrm{P}(\mathrm{HSA}-\mathrm{SA})$ in $0.1 \mathrm{M}$ $\mathrm{pH} 7.4$ phosphate buffer at $37^{\circ} \mathrm{C}$

hydrophobic monomer HSA and traces of sebacic acid. It has been reported that although significant hydrolysis of the polyanhydride occurred within the first day, the matrices remained physically intact and the watersoluble tracer released for several days and micro size pores developed throughout the polymer matrix ${ }^{[9]}$. Our results also suggest that although at $\mathrm{pH} 7.4$ almost all the weight loss was accounted for by the release of entire SA content, the device was intact with pores and comprising primarily of HAS.

In vitro drug release: The drug release rates decrease with the increase of 2-hexadecylsuccinic acid in the polymer.

As the polymer undergoes hydrolysis, watersoluble compounds (SA and drug) will be released rapidly creating pores in the device, which will be penetrated by water rapidly resulting in accelerated erosion. After 9-10 days hydrolysis the remnant 2hexadecylsuccinic acid retarded erosion and entrapped traces of drug which was slowly released (Fig. 5).

Simulation of cumulative release as function of release time was performed using a first order release 
Am. J. Applied Sci., 4 (3): 128-132, 2007

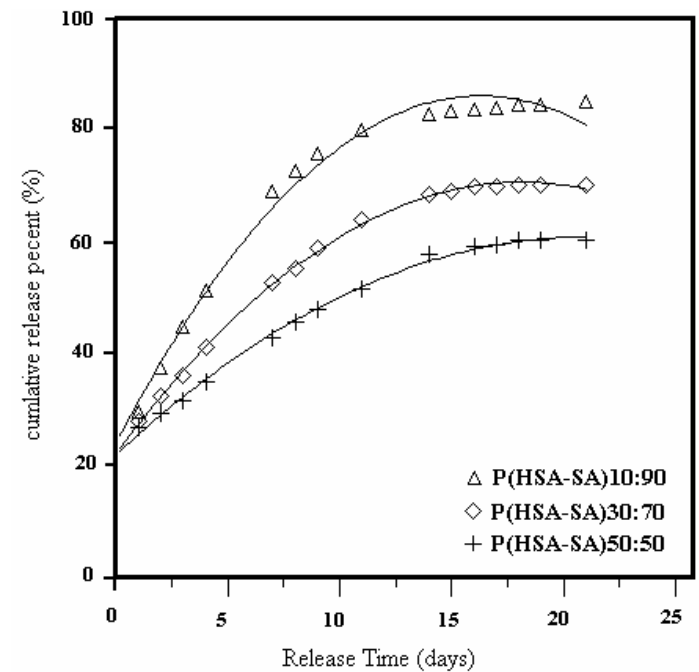

Fig. 5: Ciprofloxcin hydrochloride release profile from $0.1 \mathrm{M} \mathrm{pH} 7.4$ phosphate buffer at $37^{\circ} \mathrm{C}$

Table 2: Fitting data using frist-oreder equation for $20 \%$ drugloading devices

\begin{tabular}{|c|c|c|c|c|}
\hline \multirow{2}{*}{$\begin{array}{l}\text { Polymer } \\
\text { Composition } \\
(\mathrm{HSA} / \mathrm{SA}, \mathrm{w} / \mathrm{w})\end{array}$} & \multicolumn{3}{|c|}{$\mathrm{Y}=\mathrm{q}+\mathrm{bt}+\mathrm{ct}^{2}$} & \multirow{2}{*}{$\begin{array}{l}\text { Coefficient } \\
\text { (r2) }\end{array}$} \\
\hline & $\mathrm{a}$ & $\mathrm{b}$ & $\mathrm{c}$ & \\
\hline $\begin{array}{l}\text { HSA-SA) } 10: 90 \\
\end{array}$ & -1.294 & 12.11 & -0.3719 & 0.987 \\
\hline (HSA-SA) $30: 70$ & -4.548 & 8.524 & -0.2353 & 0.998 \\
\hline (HSA-SA) 50:50 & -4.794 & 5.875 & -0.1395 & 0.997 \\
\hline
\end{tabular}

kinetics equation $\mathrm{Y}=\mathrm{a}+\mathrm{bt}+\mathrm{ct}^{2}$ ( $\mathrm{Y}$ is the cumulative release percent and $\mathrm{t}$ is the corresponding sustained release time). As shown in Table 2 the release profiles correlate first-order release kinetics.

\section{CONCLUSION}

Poly(2-hexadecylsuccinic acid-sebacic acid) (P(HSA-SA)) were successfully prepared by melt polycondensation with high molecular weights range from 15340 to over 39000 and high yields. The copolymers were characterized by FT-IR, ${ }^{1} \mathrm{HNMR}$, gel permeation chromatography (GPC), differential scanning calorimetry (DSC and thermal gravimetric analysis (TGA). All the prepared copolymers possess low melting points, desired thermal stability, degradability and relatively steady release rate for hydrophilic model drug, ciprofloxcin hydrochloride. All these results showed that the copolymers might be potential candidates for the delivery of hydrophilic drugs locally.

\section{ACKNOWLEDGEMENT}

The financial support from Ministry of Education, P. R. China is gratefully acknowledged.

\section{REFFERENCES}

1. Leong, K.W., P.D. Amore, M. Marletta and R. Langer, 1986. Bioerodible polyanhydrides as drugcarrier matrices. II. Biocompatibility and chemical reactivity. J. Biomed. Mater. Res., 20: 51-64.

2. Laurencin, C., A. Domb, C. Morris, V. Brown, M. Chasin, R. McConnel, N. Lange and R. Langer, 1990. Poly (anhydride) administration in high doses in vivo: studies of biocompatibility and toxicology. J. Biomed. Mater. Res., 24: 1463-81.

3. Teomim, D. and A.J. Domb, 2001. Nonlinear fatty acid terminated polyanhydrides.

Biomacromolecules, 2: 37-44.

4. Domb, A.J. and M. Maniar, 1993. Degradable polymer blends. I. Screening of miscible polymers. J. Polym. Sci., Part A: Polym. Chem., 31: 1973-81.

5. Domb, A.J. and R. Nudelman, 1995. Biodegradable polymers derived from natural fatty acids. J. Polym. Sci., Part A: Polym. Chem., 33: 717-25.

6. Teomim, D., A. Nyska and A.J. Domb, 1999. Ricinoleic acid-based biopolymers. J. Biomed. Mater. Res., 45: 258-267.

7. Gouin, S., X. Zhu and S. Lhnert, 2000. New polyanhydrides made from a bile acid dimer and sebacic acid. Macromolecules, 33: 5379-5383.

8. Teomim, D. and A.J. Domb, 1999. Fatty acid terminated polyanhydrides. J. Plym. Sci., Part A: Polym. Chem., 37: 3337-3344.

9. Dang, W.B. and W.M. Saltzman, 1994. Controlled release of macromolecules from a degradable polyanhydride matrix. J. Biomater. Sci. Polym. Ed., 6: 297-311. 